\title{
UJI PERFORMANSI ALAT GREEN HOUSE EFFECT (GHE) VENT DRYER DENGAN PENAMBAHAN BATU SERPIHAN SEBAGAI MEDIA PENYIMPAN PANAS
}

(GREEN HOUSE EFFECT (GHE) VENT DRYER PERFORMANCE TEST WITH ADDITION OF FLAKE AS A HEAT STORAGE MEDIA)

\author{
Faizil Akmal ${ }^{1}$,Mustaqimah ${ }^{1}$, Diswandi Nurba ${ }^{1} *$ \\ ${ }^{1}$ Program Studi Teknik Pertanian, Fakultas Pertanian, Universitas Syiah Kuala \\ *Corresponding author: mustaqimah@unsyiah.ac.id
}

\begin{abstract}
Abstrak. Proses pengeringan ikan yang dilakukan masyarakat umumnya menggunakan cara tradisional dan menimbulkan masalah terhadap kehigienitas produk. Penelitian ini menggunakan alat pengering Green House Effect (GHE) Vent Dryer. Penggunaan alat Pengering Green House Effect (GHE) vent dryer yang memanfaatkan energi surya pada proses pengeringan dianggap sangat solutif dan tepat guna. Akan tetapi karena energi surya terbatas oleh waktu maka penggunaan media penyimpan panas sangat membantu proses pengeringan. Tujuan penelitian ini adalah menganalisa kinerja GHE vent dryer dengan menambahkan serpihan batu sebagai media penyimpan panas. Pengukuran dimulai dari pukul 08.00 WIB sampai sahu didalam ruangan menyamai suhu lingkungan, proses pengukuran dilakukan setiap 60 menit. pengukuran yang dilakukan antara lain: Suhu Absorber, suhu rak 1, rak 2 dan rak 3 pada ruang pengering, suhu lingkungan dan kecepatan udara. Hasil penelitian yang di dapatkan suhu rata-rata absorber pada alat pengering yang menggunakan batu serpihan ini berkisar $27^{\circ} \mathrm{C}$ sampai $54^{\circ} \mathrm{C}$ dengan temperatur lingkungan yang di hasilkan $24^{\circ} \mathrm{C}$ sampai $31^{\circ} \mathrm{C}$,dan untuk terperatur dalam alat pengering sekitar $23^{\circ} \mathrm{C}$ sampai $50^{\circ} \mathrm{C}$. Hasil pengukuran kecepatan udara pada penelitian ini berkisar $0,2 \mathrm{~m} / \mathrm{s}$ sampai $1,7 \mathrm{~m} / \mathrm{s}$. Dapat disimpulkan bahwa penambahan batu serpihan sebagai media penyimpan panas pada alat GHE vent Dryer dapat mempertahankan panas pada ruang pengering selama 3 sampai 4 jam saat tidak ada radiasi matahari.
\end{abstract}

Kata Kunci: suhu, aliran udara, energi, media penyimpan panas, batu serpih

Abstract. The fish drying process carried out by the community generally uses traditional methods and causes problems with product hygiene. This research uses the Green House Effect (GHE) Vent Dryer dryer. The use of the Green House Effect Dryer (GHE) vent dryer that utilizes solar energy in the drying process is considered very solution and efficient. However, because solar energy is limited by time, the use of heat storage media really helps the drying process. The purpose of this study was to analyze the performance of the GHE vent dryer by adding stone chips as a heat storage medium. The measurement starts from 08.00 WIB until the temperature in the room equals the ambient temperature, the measurement process is carried out every 60 minutes. Measurements made include: Absorber temperature, shelf temperature 1, shelf 2 and shelf 3 in the drying chamber, ambient temperature and air velocity. The results obtained that the average temperature of the absorber in the dryer using this flake stone ranged from $27^{\circ} \mathrm{C}$ to ${ }^{54 \mathrm{C}}$ with the resulting ambient temperature of $24^{0} \mathrm{C}$ to $31^{\circ} \mathrm{C}$, and for a regular temperature in the dryer it was around $23^{\circ} \mathrm{C}$ to $50^{\circ} \mathrm{C}$. The results of air velocity measurements in this study ranged from $0.2 \mathrm{~m} / \mathrm{s}$ to $1.7 \mathrm{~m} / \mathrm{s}$. It can be concluded that the addition of crushed stone as a heat storage medium in the GHE vent Dryer can maintain heat in the drying chamber for 3 to 4 hours when there is no solar radiation.

Keywords: temperature, air flow, energy, heat storage medium, shale. 


\section{PENDAHULUAN}

Pengeringan merupakan proses pengeluaran air dari suatu bahan pertanian menuju kadar air kesetimbangan dengan udara sekeliling atau pada tingkat kadar air tertentu sehingga dapat memperlambat laju kerusakan produk akibat dari serangan jamur, enzim, dan aktivitas serangga (Hederson dan Perry, 1976 dalam Witarsa, 2004). Namun kini telah banyak dikembangkan metode pengeringan mekanis dan semi mekanis yang relatif murah dan cukup efektif dalam mengatasi berbagai kendala pada penjemuran yaitu fluktuasi radiasi surya,kebutuhan lahan luas,situasi cuaca yang berubah-ubah, adanya kontaminasi mikroorganisme, hewan, dan berbagai reaksi kimia lainnya(Irfan khalil. F. et al. 2016)

Dalam proses pengeringan, pemanfaatan sinar matahari sangat mudah dilakukan dan biaya yang relatif murah, namun terdapat kekurangan apabila terjadi kondisi yang tidak mendukung ketika terjadi perubahan cuaca. Pengeringan dengan kolektor surya pelat datar yaitu dengan menyerap energi panas yang melewati penutup transparan oleh absorber yang berupa pelat hitam (Ankira E. N. Saputro. 2014). Pada bagian absorber diletakkan batu serpihan dimana penggunaan batu serpihan bisa menjadi solusi karena dapat dimanfaatkan sebagai media penyimpan panas yang sangat berguna dalam proses pengeringan.

Proses pengeringan yang dilakukan masyarakat umumnya menggunakan cara tradisional dan menimbulkan masalah dalam kehigienitas produk. Akan tetapi karena energi surya terbatas oleh waktu maka penggunaan media penyimpan panas sangat membantu keberlangsungan proses pengeringan. Media Penyimpan panas berperan untuk mengurangi fluktuasi suhu dalam ruang alat pengering, mengurangi kelebihan suhu dan menyimpan panas agar proses pengeringan tetap berjalan meskipun panas dari matahari tidak ada (Astawa K.et al 2014).

Penelitian ini menganalisis performa GHE vent dryer dengan menambahkan serpihan batu sebagai media penyimpan panas. Batu serpihan (shale) biasanya batu ini di sebut juga sebagai batu lamau atau argilit, batu serpih juga didefinisikan sebagai jenis batuan sendimen yang tersusun dari mineral utama yang berukuran halus atau lempung yaitu berupa ilite, smektit, kaolinit, serta mineral dengan butiran berat seperti oksidasi besi, kuarsa, karbonat, mineral sulfide, feldspar dan bahan organik lainnya. Komposisi mineral-mineral tersebut tergantung tempat atau lingkungan terjadinya proses sendimen atau pengedapan (Suhendra. Feby Nopriandy. 2018). Jadi nilai konduktivitas batu dapat dilihat pada tabel 1 .

Tabel. 1 Konduktivitas termal untuk berbagai bahan (Zemansky, 2002)

\begin{tabular}{|c|c|c|c|}
\hline Logam & & Lain-lain & \\
\hline Aluminium & 205,0 & Bata merah & 0,6 \\
\hline Kuningan & 109,0 & Bata isolasi & 0,15 \\
\hline Tembaga & 385,0 & Beton & 0,8 \\
\hline Timbal & 34,7 & Gabus & 0,04 \\
\hline Perak & 406,0 & Kaca & 0,8 \\
\hline Baja & 50,2 & Batu & 0,04 \\
\hline Raksa & 8,3 & Styrofoam & 0,01 \\
\hline \multirow[t]{2}{*}{ Besi } & 73 & Lilin & 0,02 \\
\hline & & kayu & 0,21 \\
\hline
\end{tabular}




\begin{tabular}{ll}
\hline Gas & \\
Udara & 0,024 \\
Argon & 0,016 \\
Helium & 0,14 \\
Hidrogen & 0,14 \\
Oksigen & 0,023 \\
\hline
\end{tabular}

Tabel 1 menjelaskan bahwa bahan yang memiliki konduktivitas besar merupakan konduktor yang baik dan sebaliknya bahan yang memiliki konduktivitas kecil merupakan konduktor yang jelek. Nilai konduktifitas suatu batu senilai 0,04, Jadi penggunaan batu serpihan sangat bagus digunakan dikarnakan batu serpihan ketika menyimpan panas proses penghantaran panasnya perlahan-lahan sehingga suhu dalam alat pengering GHE vent dryer lebih stabil.

\section{METODE PENELITIAN}

Alat yang digunakan dalam penelitian ini adalah termometer, anemometer,solarimeter, dan alat pendukung lainnya. Sedangkan bahan yang digunakan dalam penelitian adalah batu serpihan.

\section{Prosedur Penelitian}

Dipersiapkan batu serpihan yang sudah di potong dengan ukuran $3 \mathrm{~cm}$ sampai $5 \mathrm{~cm}$ dengan jumlah batu yang diperlukan sebanyak $15 \mathrm{Kg}$ serta peletakan batu serpihan didalam keranjang besi yang di susun 3 keranjang pada ruang absorber dapat dilihat pada gambar 2 . Pada penelitian ini dilakukan pengujian performansi sistem penyimpan panas pada alat GHE Vent Dryer dengan dilakukan pengukuran temperatur absorber, temperatur rak 1, rak 2, rak 3 pada ruang pengering serta temperatur lingkungan dapat dilihat pada gambar 1. dengan pegambilan data 60 menit per jam yang berlansung selama 3 hari dimulai pukul 08.00 sampai pukul 22.00 WIB. Proses pengukuran menggunakan Alat ukur yang dipasang didalam dan di luar alat pengering serta mengamati data yang telah diukur sampai suhu alat pengering menyamai suhu lingkungan.

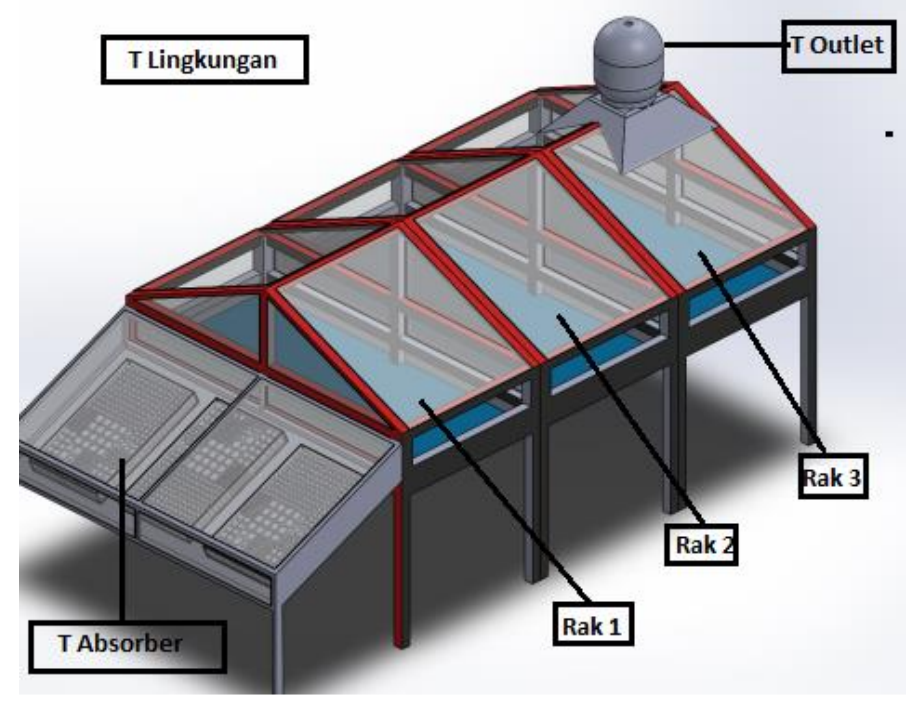

Gambar 1 . Titik-titik Pengukuran 


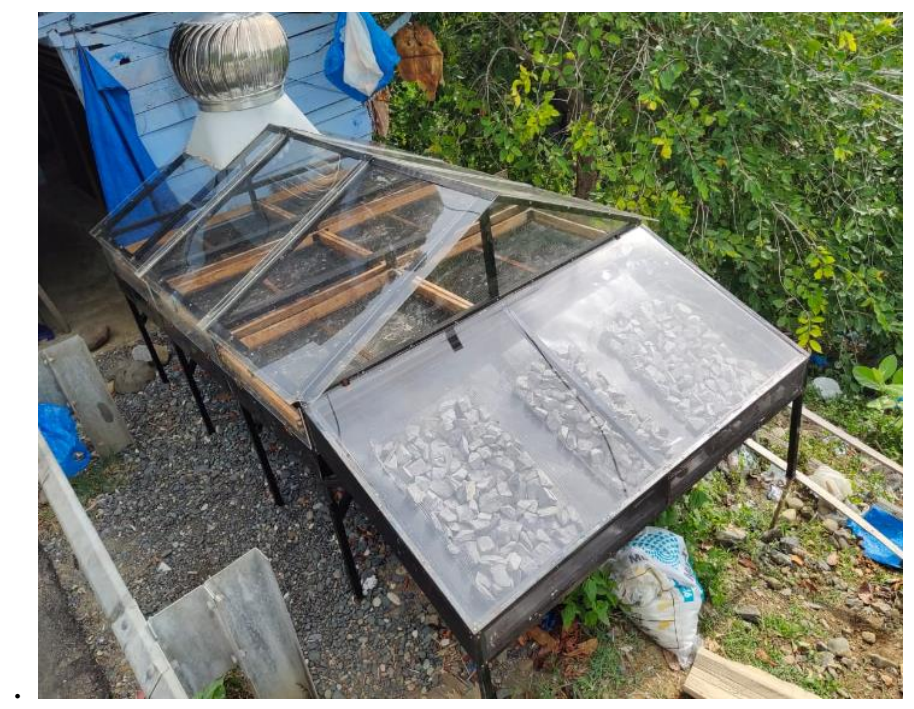

Gambar 2. Nampak peletakan batu pada ruang absorber

\section{HASIL DAN PEMBAHASAN}

\section{Penggunakan media penyimpan panas berupa batu serpihan}

Batu serpihan yaitu memiliki pangaruh berbeda terhadap kondisi pada saat penyerapan energi matahari dikarenakan batu serpihan memiliki sendimen yang serentak sehingga perpindahan panas pada batu tersebut dapat memindahkan energi panas kelingkungan kecil seperti pada alat pengering secara bertahap. Gambar 3 adalah tampak batu yang digunakan pada penelitian ini.

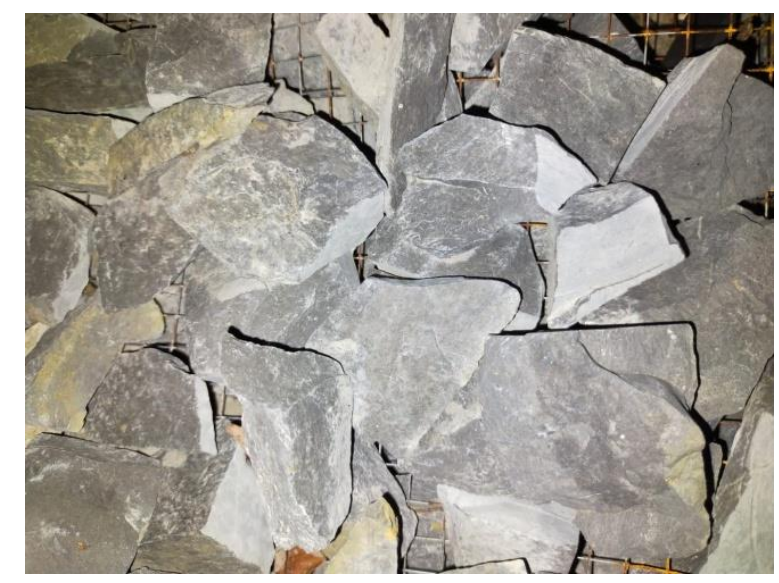

Gambar 3. Batu Serpihan Sebagai Media Penyimpan Panas. 


\section{Temperatur Absorber}

Absober adalah bagian yang sangat penting pada alat GHE Vent dryer. Absorber berfungsi sebagai penyerap panas matahari untuk disalurkan ke dalam ruang pengering. Ratarata temperatur absorber dengan menggunakan media penyimpan panas berupa batu serpihan $27^{\circ} \mathrm{C}$ sampai $54^{\circ} \mathrm{C}$.

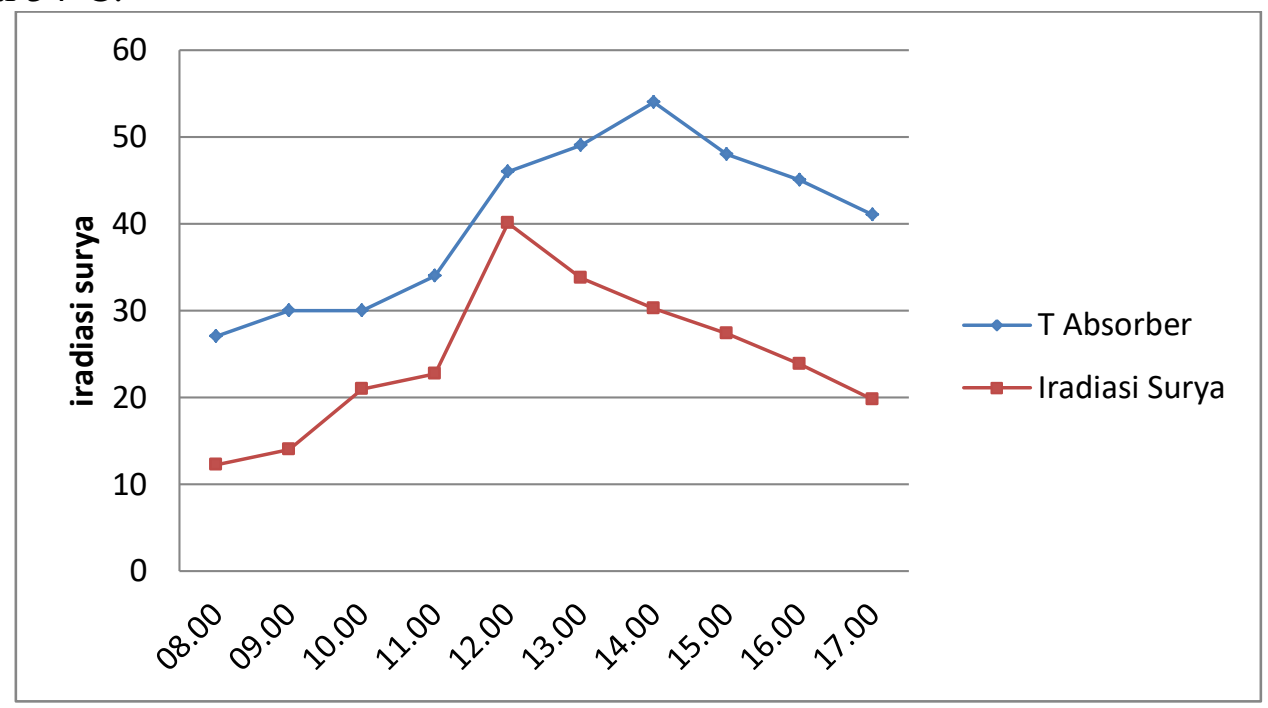

Gambar 4. Suhu absorber pada ruang pengering GHE vent dryer

Gambar 4. menunjukan bahwa temperatur pada ruang absorber lebih stabil saat penurunan energi matahari, proses awal pengukuran pada pukul 08.00-12.00 WIB dimana temperatur mengalami kenaikan yang stabil pada puncak panas siang hari, pada sore hari pukul 18.00-22.00 WIB temperatur ruang absorber dengan menggunakan media penyimpan panas berupa batu serpihan lebih relatif stabil dikarenakan sebagian kalor masih tersimpan pada batu serpihan sehingga ruang absorber masih memancarkan panas pada saat malam hari. Sesuai dengan pernyataan dari Sitepu (2012), kondisi cuaca yang berawan menyebabkan hasil pengukuran radiasi matahari menjadi lebih rendah dari pada kondisi cuaca normal.

\section{Distribusi Suhu}

Pengukuran suhu ruang pengering dilakukan pada 6 titik pengukuran dimana Distribusi suhu ini pada saat pengujian suhu tertinggi absorber ketika menggunakan media penyimpan panas berupa batu serpihan, suhu ruang pengering pada rak 1 adalah $49^{\circ} \mathrm{C}$, rak 2 adalah $52^{\circ} \mathrm{C}$ serta rak 3 adalah $51^{\circ} \mathrm{C} 67^{\circ} \mathrm{C}$ dengan pancaran iradiasi sebesar $6,9 \mathrm{~W} / \mathrm{m}^{2}$, suhu tertinggi terjadi pada siang hari kemudian suhu turun perlahan-lahan seiring berjalannya waktu sampai pada malam hari, ketika suhu ruang pengering sudah menyamai suhu lingkungan. 


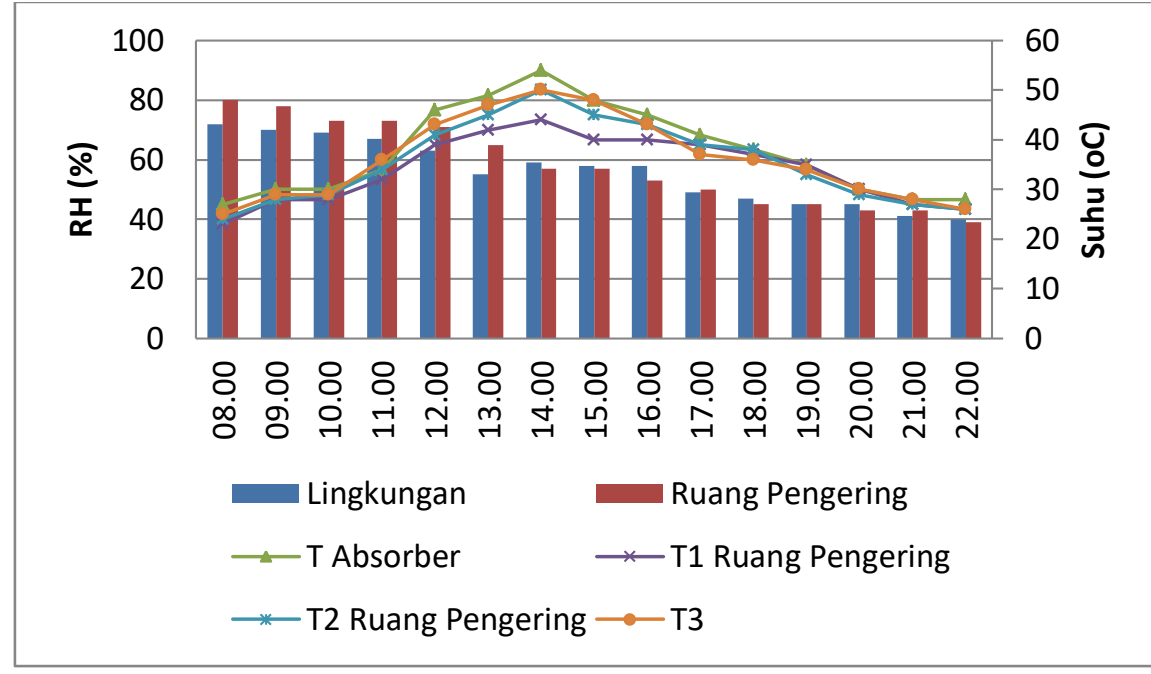

Gambar 5. Distribusi Suhu Alat pengering GHE

Gambar 5 menunjukkan perbandingan antara suhu lingkungan dan suhu di dalam ruang pengering. Pada gambar diatas dapat dilihat bahwa suhu selama proses pengeringan memiliki pola yang seragam dimana pada pengujian alat pengering GHE vent dryer yaitu pada pukul 08.00 WIB penyebaran suhu lingkungan yaitu $24^{\circ} \mathrm{C}$ sedangkan suhu absorber berkisar $27^{\circ} \mathrm{C}$ ini menandakan bahwa dengan penambahan media penyimpan panas suhu dalam alat pengering lebih tinggi dibandingkan dengan suhu lingkungan. Suhu tertinggi pada pengujian ini yaitu pada pukul 14.00 WIB dengan suhu absorber $54^{\circ} \mathrm{C}$, dengan suhu lingkungan $31^{\circ} \mathrm{C}$ semakin tinggi suhu maka semakin kecil juga kelembaban yang di dapatkan. Menurut Resmi (2014) menjelaskan bahwa penggunaan suhu yang terlalu rendah yang mengakibatkan waktu proses pengeringan yang sedikit lebih lama, sedangkan jika suhu tinggi itu dan mengakibatkan tekstur kualitas bahan menjadi buruk.

\section{Kecepatan Aliran Udara}

Kelembaban udara sangat berpengaruh terhadap proses pengeringan, karena kelembaban udara menunjukkan kandungan air yang terdapat di udara. Kandungan udara yang tinggi akan mempengaruhi proses pengeringan sehingga pengeringan akan berlangsung lebih lama dan begitu juga sebaliknya apabila kelembaban udara rendah maka akan mempercepat proses pengeringan (Irawati et al. 2008).

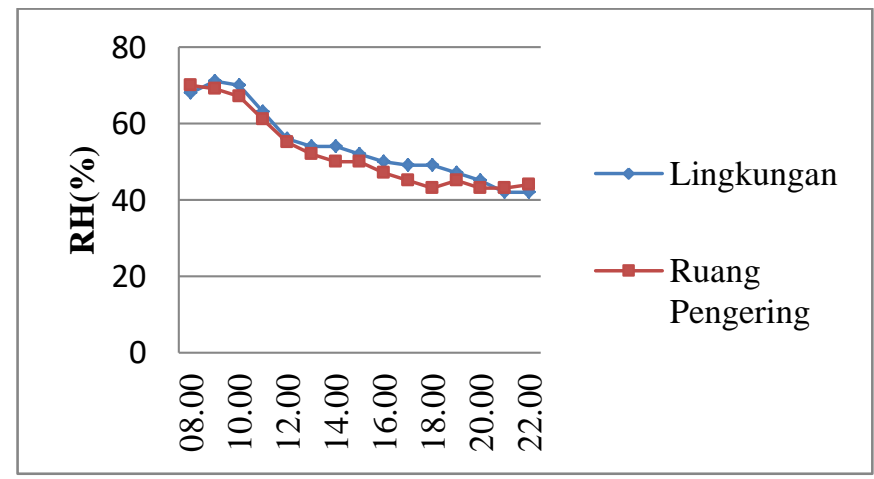

Gambar 6. Kelembaban alat pengering 


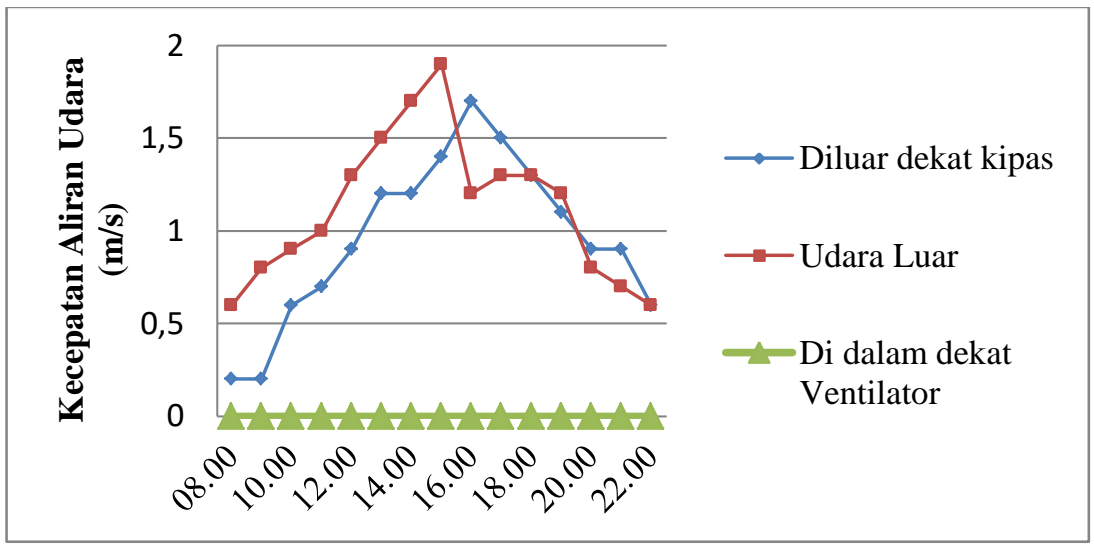

Gambar 7. kecepatan Aliran udara

Gambar 7 menjelaskan bahwa kecepatan aliran udara dari pukul 08.00 WIB sampai pukul 15.00 WIB mengalami kenaikan, dengan laju aliran udaranya 0,6 m/s sampai 1,7 m/s. Aliran kecepatan udara berubah-rubah seketika dikarenakan letak alat pengering dekat dengan pantai hal ini mengakibatkan aliran udara lebih tinggi. Menurut Syah (2012), prinsip pengeringan yaitu perpindahan air yang terdapat didalam bahan kelingkungan sekitar, prinsip pengeringan dimulai dengan adanya hembusan panas udara dan kering terhadap bahan pangan. Interaksi bahan dengan udara dapat menciptakan suasana yang konduktif supaya terjadinya penguapan air hingga terjadi perpindahan massa dan panas yang simultan.

Gambar 6 menjelaskan kelembaban pada saat itu tergantung cuaca maupun iklim sekitar dimana kelembaban ruang pengering lebih kecil di bandingkan dengan kelembaban lingkungan dikarnakan temperatur di dalam alat pengering lebih panas sehingga kelembaban di dalam alat pengering lebih rendah, kelembaban ini juga berlaku dimalam hari dimana pada malam hari kelembaban lingkungan berbeda dengan kelembaban di dalam alat pengering karena di dalam alat pengering memiliki temperatur yang dikeluarkan oleh media penyimpan panas yaitu batu serpihan sehingga membuat kelembaban semakin rendah Dapat diambil kesimpulan bahwa perpindahan panas terjadi akibat adanya perbedaan suhu antara bahan dengan udara yang masuk, hal ini sesuai dengan pernyataan Kartasapoetra (2004), menjelaskan bahwa selama siang hari sampai dengan pukul $\pm 15.00 \mathrm{WIB}$ lebih banyak energi yang diterima bumi daripada yang diradiasikan matahari. Pada malam hari energi bumi hilang terus menerus melalui radiasi bumi yang mengakibatkan pendinginan dari permukaan dan penurunan temperatur. Semakin tinggi iradiasi surya maka suhu udara akan semakin tinggi pula. Udara yang bersuhu tinggi lebih cepat mengambil air dari bahan pangan sehingga proses pengeringan menjadi lebih cepat. proses perpindahan massa terjadi sebab adanya perbedaan konsentrasi air antara bahan pangan dengan udara masuk (Ratna sary, 2016)

\section{KESIMPULAN DAN SARAN}

\section{Kesimpulan}

Berdasar hasil penelitian dapat di simpulkan bahwa:

1. Penambahan media penyimpan panas berupa batu serpihan berjalan dengan baik dalam menyimpan dan mendistribusikan udara panas dari ruang absorber ke ruang pengering

2. Penggunaan batu serpihan sebagai media penyimpan panas pada alat GHE vent Dryer mampu mempertahankan panas pada ruang pengering selama 3 sampai 4 jam saat tidak ada radiasi matahari 
3. Perubahan cuaca ataupun iklim sangat mempengaruhi temperatur absorber dan ruang pengering maka dari itu pemilihan media penyimpan panas adalah tindakan yang tepat.

\section{Saran}

Di harapkan melakukan penelitian lebih lanjut untuk mempertahankan suhu dalam alat pengering lebih lama lagi, dimana dengan menutup saluran udara ruang absorber pada saat malam hari, sehingga suhu absorber dan ruang pengering lebih lama serta menambakan media penyimpan panas baerupa batu serpihan lebih banyak lagi.

\section{DAFTAR PUSTAKA}

Ankira E. N. Saputro. 2014. Pengaruh Sudut Kaca Penutup dan Jenis Kaca Terhadap Efisiensi Kolektor Surya Pada Proses Destilasi Air Laut. Fakultas sains dan Teknik. Universitas Nusa Cendana. NTT.

Astawa K., Tista S.P.G,. Saputra I.W.H., 2014, Analisis Performansi Kolektor Surya Pelat Datar Dengan Media Penyimpan Panas Pasir Untuk Pemanas Udara. Jurnal Teknika (jurnal Ilmiah Teknik), Vol. 10, No. 1, Hal. 43-50.

Nopriandy. F. 2018. Analisi Penggunaan Batu Serpih Sebagai Media Penyimpan Panas Pada Kolektor Surya. Jurusan Teknik Mesin. Universitas Muhammadiyah Metro. Kalimantan Barat.

Irawati., Rahardjo,B., dan Bintoro, N.,(2008) Perpindahan Massa pada Pengeringan Vakum disertai Pemberian Panas Secara Konvektif, Prosiding Seminar Nasional Teknik Pertanian: Yogyakarta.

Irfan khalil. F. et all. 2016. Desain Sistem Kendali Untuk Pengering Gabah Dengan Kolektor Surya dan Penyimpan Panas. Program Studi Teknik Pertanian dan Panga. Institut Pertanian Bogor.

Kartasapoetra, A.G. 2004. Pengaruh Iklim Terhadap Tanah dan Tanaman. Bumi Aksara, Jakarta

Nelwan L.O. 1997. Pengeringan Kakao dengan Energi Surya Menggunakan Rak Pengering dengan Kolektor Tipe Efek Rumah Kaca. Tesis . Program Pasca Sarjana. IPB Bogor.

Nitipraja,F, A., 2008. Rancangan Alat Pengering Dengan Kolektor Plat Datar Yang Menggunakan Air Sebagai Media Penyimpan PanasUntuk Pengeringan Gabah. Departemen Teknik Pertanian, Fakultas Teknologi pertanian. Institut Pertanian Bogor.

Sari. R. 2016. Kaji Eksperimental Pengeringan Biji Kopi Dengan Menggunakan Sistem Konveksi Paksa. Teknik Pertanian. Universitas Syiah Kuala. Banda Aceh

Resmi. 2014. Pengaruh Suhu dan Lama Pengeringan Terhadap Karakteristik Jamur Tiram Putih Kering. Skripsi. Universitas pasundan. Bandung.

Sitepu, T. (2012). Pengujian mesin pengering kakao energi surya. Jurnal Dinamis.

Suhendra. 2018. Analisi Penggunaan Batu Serpih Sebagai Media Penyimpan Panas Pada Kolektor Surya. Jurusan Teknik Mesin. Universitas Muhammadiyah Metro. Kalimantan Barat.

Syah, D. 2012. Pengantar Teknologi Pangan. PT Penerbit IPB Press. Bogor.

Zemansky, 2002.Kalor dan Termodinamika.ITB. Bandung. 